\title{
Occlusal force evaluation and its clinical implication in dental clinics
}

\author{
Jin-Kyu Kang ${ }^{1,2}$ and Jin-Han Lee ${ }^{2,3 *}$ \\ ${ }^{1}$ Professor, Department of Orofacial Pain and Oral Medicine, Wonkwang University Daejeon Dental Hospital, Daejeon, Republic of Korea \\ ${ }^{2}$ Wonkwang Dental Research Institute, Wonkwang University, Iksan, Republic of Korea \\ ${ }^{3}$ Professor, Department of Prosthodontics, Wonkwang University Daejeon Dental Hospital, Daejeon, Republic of Korea
}

Occlusal force is defined as the force resulting from an interaction between upper and lower teeth, bones, and muscles. The amount of occlusal force is mainly determined by the condition of masticatory muscles and affected by various factors, such as age, sex, craniomandibular morphology, dentition, and periodontal support. The maximum bite force is used as an indicator of the functional state of the masticatory system, and the association between occlusal force and various dental clinical procedures has been reported. In this article, we aim to review the implication of occlusal force in dental clinical settings. We summarize various methods and considerations for measuring occlusal force and investigate the relationship between occlusal force and clinical practices, including orthodontic treatment, orthognathic surgery, prosthetic restoration, and temporomandibular disorders.

Key Words: Bite force; Dental clinic; Occlusal force

(c) This is an open-access article distributed under the terms of the Creative Commons Attribution Non-Commercial License (http://creativecommons.org/licenses/by-nc/4.0) which permits unrestricted noncommercial use, distribution, and reproduction in any medium, provided the original work is properly cited.

\section{Introduction}

치과에 방문하는 환자의 대부분은 치아나 치아지지 조직의 통증이나 불편함을 주소로 내원한다. 이러한 통증이나 불편함 으로 인해 환자의 저작기능은 제한되며 잘 씹지 못함을 호소하 게 된다. 교합력은 대합치에 가해지는 저작근의 근육 활동 결과 이며, 음식이나 기타 물질을 저작할 때 대합치나 지지 조직에 미 치는 힘이다. 교합력의 크기는 주로 저작계 근육의 능력에 따라 달라지는데 이는 근섬유의 양, 근육의 크기, 근육의 주행방향 등 에 의해 결정된다. 또한, 교합력은 연령, 성별, 안면골격구조, 치 아와 치열의 상태, 치주조직의 지지, 측두하악장애 등 여러 다양 한 저작계 요소에 의해 영향을 받게 되어 임상적으로 중요한 의 미를 갖게 된다[1,2]. 그러므로 교합력의 분석은 저작계의 기능 을 평가하는 수단으로 사용되어 오랜 기간 동안 교합력을 측정
하기 위한 많은 방법과 장비들이 개발되어 왔고, 여러 문헌을 통 해 보고되어 왔다. 이 논문에서는 치과 임상에서 교합력의 의미 와 측정방법에 대해 고찰하고, 치아교정 및 턱교정 수술, 수복치 료, 측두하악장애 등의 임상술식과 교합력의 연관성 및 그 평가 와 고려사항 등에 대해 알아보고자 한다.

\section{Main Body}

\section{교합력}

교합력은 개인별로 다르며, 대개 남성이 여성에 비해 강한 교 합력을 나타낸다[2,3]. 또한, 구치부는 전치부에 비해 훨씬 더 강 한 힘을 나타낸다고 보고되어 왔다[4]. Waltimo와 Könönen [5] 의 연구에 의하면 구치부 최대 교합력은 남성에서 $847 \mathrm{~N}$, 여성

Received November 12, 2021; Revised December 2, 2021; Accepted December 8, 2021

*Corresponding author: Jin-Han Lee, Department of Prosthodontics, Wonkwang University Daejeon Dental Hospital, 77, Dunsan-ro, Seo-gu, Daejeon 35233, Republic of Korea

Tel: +82-42-366-1155, Fax: +82-42-366-1115, E-mail: porte93@wku.ac.kr 
에서 597 N이며, 전치부 최대 교합력은 남성에서 $287 \mathrm{~N}$, 여성 에서 $243 \mathrm{~N}$ 으로 나타나 전치부의 최대 교합력은 구치부의 $1 / 3$ 정도로 보고되었다. Kovero 등[6]의 연구에서도 핀란드인의 구 치부 최대 교합력은 남성에서 $844 \mathrm{~N}$, 여성에서 $683 \mathrm{~N}$ 으로 나타 났고, 전치부 최대 교합력은 남성에서 $286 \mathrm{~N}$, 여성에서 $237 \mathrm{~N}$ 으로 이전 연구와 유사하게 나타났다. Kiliaridis 등[7]은 미국인 에서 남성의 최대 교합력은 $807 \mathrm{~N}$, 여성의 최대 교합력은 650 $\mathrm{N}$ 으로 보고하였다. 또한, 구치부의 최대 교합력을 연령에 따라 분석하였을 때, 7-9세는 385-610 N, 10-13세는 450-680 N, 성인에서는 420-650 N으로 나타났고, 전치부의 최대 교합력은 각 연령대에서 60-130 N, 110-160 N, 160-270 N으로 보고 되어 성장기에는 연령의 증가에 따라 최대 교합력이 증가하는 경향을 나타냈다[7]. 기타 여러 연구에서 유치열기부터 20세까 지 최대 교합력이 증가하다가 이후 감소하는 경향을 나타냈다 $[8,9]$.

한국인을 대상으로 시행한 연구에서 남자의 최대 교합력은 $644 \mathrm{~N}$, 여자의 최대 교합력은 $441 \mathrm{~N}$ 으로 나타나 한국인의 최대 교합력이 서양인에서의 계측값보다 작게 나타난 경향이 있는데 저자들은 측정기에 따른 물리적 특성의 차이, 표본의 신체적 조 건의 차이 등에 의해 기인한 것으로 분석하였다[10]. 교합력 측 정은 사용한 측정장비, 측정방법, 측정부위 등에 따라서도 결과 가 상이하게 나타날 수 있고, 개인별로도 측정 시기에 따라서 측 정값이 달라질 수 있으므로 이러한 요인을 고려하여 교합력 측 정값을 비교할 때에는 주의를 기울여야 한다.

\section{교합력 측정방법}

교합력의 측정은 저작계의 기능과 효율성을 평가하기 위해 서 오래전부터 시도되어 왔고, 교합력을 객관적인 수치로 기록 하기 위한 다양한 장비들이 개발되었다. 교합력의 측정방법은 대합관계에 있는 치아 사이에 기구를 위치시킴으로써 교합력을 직접 측정하는 방법과 교합 시 발생하는 음파 진동을 증폭하여 분석하거나 저작근의 표면에서 근전도 기록을 분석하는 간접적 인 방법이 있다[11,12]. 간접적인 방법은 치아 사이에 개재되는 측정기구 없이 최대 교두간접촉 상태에서 교합력을 측정할 수 있는 장점이 있으나, 환자마다 다양한 해부학적, 생리적 요인으 로 인해 측정과 분석에서 오차가 크다는 단점이 지적되었다. 구 강 내에서 직접 측정하는 방법은 대합 치아 사이에 측정 기구가 개제되는 단점이 있으나, 간접적인 방법에 비해 측정기구의 적 용이 용이하고 비용이 저렴하다는 장점이 있고, 기술이 발달함 에 따라 측정기구의 두께가 얇아지면서 교합력 연구에 많이 사 용 되고 있다.

교합력 측정 장치에는 기계식 장비나 전기식 장비 또는 복합
방식의 장비가 사용되어 왔고, 최근에는 컴퓨터를 이용한 방식 이 사용되고 있다. Borelli는 gnathodynamometer라는 장치를 고안하여 대구치 부위에서 폐구 시에 무게추를 들어 올리는 방 식으로 구강 내에서 교합력을 처음으로 측정하였고, Black은 gnathodynamometer에 레버 스프링과 압력계 스프링, 그리고 측미계(micrometer)를 추가한 장비를 개량하여 이전에 비해 좀 더 기계적으로 세밀하게 측정할 수 있도록 하였다[13].

기계적 장비에 비해 전기적 장비는 더 넓은 범위의 교합력을 더 작은 단위로 정확하게 기록하는 것이 가능하였다. 전기적 장 비들은 교합력을 전기신호로 변환하기 위한 하중센서를 사용하 였는데, 작동방식에 따라 분류된다.

스트레인게이지는 금속판의 형태를 갖는다. 하중이 가해지면 금속판에 변형이 발생하면서 길이는 증가하고, 단면적은 감소 되어 전기저항이 증가하게 된다. 전기저항측정기(Wheatstone bridge)를 사용하여 전기저항의 증가분을 계측한다. Linderholm과 Wennström [14]은 금속바로 만들어진 2개의 교합판에 스트레인게이지를 부착하고, 교합판을 금속 쐐기로 연결한 장 치를 통해서 교합판에 가해지는 교합력을 측정하였다. 스트레 인게이지를 이용한 측정 장치는 이전의 기계식 장비에 비해 더 정확하게 최대 교합력을 측정하는 것이 가능해졌으나, 금속 장 치를 깨무는 것과 그 과정에서 치아의 파절이 발생할 수 있다는 피실험자의 두려움으로 인해 최대근력이 적용되는 것에는 어려 움이 있었다. 그리고 측정장치의 금속 두께로 인해서 최대 교두 간접촉위가 아닌 상태에서 측정이 되며, 완전히 폐구가 이루어 지지 않음으로 인해 저작근의 근활성이 감소되므로 결과적으로 는 교합력이 낮게 측정되는 문제가 있었다[15].

압전결정은 석영과 같은 결정체 물질로 기계적인 응력이 가 해지면 반대편에 전위차를 발생시킨다. 압전변환기는 교합력 에 의한 변형을 민감하게 감지하기 위하여 필름형태로 되어있 다. 교합력에 의해 발생되는 전류의 양은 매우 작기 때문에 압 전전기신호를 증폭하여 기록하도록 제작되었다. 압전변환기는 $2 \mathrm{~mm}$ 이하의 두께로 제작가능하기 때문에 스트레인게이지 방 법에 비해 더 폐구된 상태에서 측정이 가능하다는 장점이 있다 [16]. 대표적으로 T Scan system (Tekscan Inc., Boston, MA, USA)이 있으며 교합접촉 부위와 시간, 교합력을 기록하는 것이 가능하다. 교합력을 측정할 때 인접한 접촉점들과 상대적 크기 측정은 가능하지만 교합력의 크기를 절대적 수치로 나타내기는 어렵다.

압력감지필름은 2 개의 폴리에틸렌으로 구성된 압력에 민감 한 편자모양의 판이다. 교합력이 가해지면 테레프탈염산 필름 사이에 놓인 마이크로캡슐이 부서지면서 내부에 있던 색소 형 성 물질이 새어나와 현상액과 반응하게 된다. 가해지는 압력에 따라 색농도가 달라진다. 교합이 기록된 압력감지필름은 분석 
기를 이용하여 교합이 이루어진 위치, 힘의 크기, 교합점의 분 포를 분석할 수 있다[17]. 대표적으로 Dental Prescale system (Fuji Film Co., Tokyo, Japan)이 있으며 얇은 두께의 압력감지 필름을 사용하여 교합력에 따른 색상의 밀도를 측정하고 교합 력의 총합 수치를 절대값으로 표시하는 것이 가능하다. 동일 환 자의 치료 전후나 여러 환자의 데이터 비교 분석이 가능한 장점 이 있다.

\section{골격 및 교합형태와 교합력}

여러 선학들의 연구를 통해 안면 골격 및 교합의 형태와 최대 교합력의 연관성에 대한 평가가 이루어졌고, 연구방법과 연구 대상의 선택, 교합력의 측정방법에 따라 다양한 결과들이 보고 되었다. 앵글 분류에 따른 교합력의 평가에서 정상 교합자가 가 장 큰 최대 교합력을 보이고, 1 급, 2 급, 3 급 부정교합의 순서로 최대 교합력을 보이는 것으로 나타났다[18]. Sathyanarayana 등[3]에 의하면 1급 부정교합과 2급 부정교합 환자의 최대 교합 력은 통계적으로 유의할만한 차이가 존재하지 않는 반면에, 장 안모 환자군의 최대 교합력은 단안모 환자군에 비해 통계적으 로 유의할만한 수준으로 낮게 나타났다. 두개안면의 형태에 따 른 교합력을 비교한 연구에서도 짧은 수직고경을 가진 사람의 최대 교합력은 긴 수직고경의 안모를 가진 사람에 비해 높게 나 타난다고 보고하였다[19]. 한편, Sonnesen과 Bakke [20]은 최 대 교합력이 앵글 분류에 따라 다르지 않고, 두부 자세와도 연관 이 없다고 보고하였다.

하지만 대부분의 연구에서 최대 교합력을 제 1 대구치 부위에 서 측정하였다는 한계점이 있다. T-scan을 통해 교합형태에 따 른 교합력의 차이를 비교한 연구에서는 앵글 3 급 부정교합과, 수평 및 수직피개량이 적은 경우 구치부의 최대 교합력이 다른 교합형태의 환자에 비해 증가된 것으로 보고하였다[21]. 이 연 구는 T-scan을 통해 전체 악궁을 평가하였지만, 최대 교합력의 수치를 평가한 것이 아니라 전치부 교합력에 대한 구치부 교합 력의 비율을 평가한 것이어서 3급 부정교합에서 이 수치의 증가 는 구치부의 교합력의 증가 의미도 있지만 전치부의 교합력이 감소한 것도 원인이 될 수 있다.

부정교합 환자의 경우 정상 교합자에 비해 최대 교합력이 낮 게 나타나는 경향이 있고, 그 원인으로 치아의 틀어짐으로 인한 치아의 교합접촉면적의 감소와 이로 인해 저작근이 최대한의 수축력을 발휘하는데에 영향을 주기 때문이라고 하였다[9]. 하 지만 이러한 교합력의 감소는 앵글 분류와 같은 골격의 형태학 적 차이뿐만 아니라 교합접촉 및 악골과 저작근계의 생역학에 의해 더욱 많은 영향을 받는다고 알려져 있고[22], 편측 구치부 반대교합의 어린이 및 전치부 개교합의 성인에서 교합력이 낮
다고 보고된 바 있다[23]. 이와 반대로 골격의 부조화가 최대 교 합력에 큰 변화를 유발하지 않는다고 보고한 연구들도 있고, 반 안면왜소증과 말단비대증 환자의 최대 교합력을 정상인과 비교 했을 때 유의한 차이가 나타나지 않았다고 보고되었다[24,25].

\section{교정치료와 교합력}

부정교합은 최대 교합력의 감소와 연관되어 있고 교정치료를 통해 최대 교합력이 증가되는 것이 많은 연구를 통해 보고되어 있다. Alomari와 Alhaija [26]는 통상적인 교정치료를 진행하며 6개월 동안 교합력의 변화를 대조군과 비교하여 보고하였는데 치료 시작 1주 후 교합력은 치료 전에 비하여 $50 \%$ 정도로 감소 하였고, 1 개월까지 지속적으로 감소하다가 이후로는 증가하여 치료 2개월 이후는 술전과 비슷한 정도로 회복되는 양상을 보였 다. 초기의 교합력 감소는 교합접촉의 영향뿐만 아니라 교정치 료 시 발생하는 통증으로 인해 저작근의 감각 유입의 변화와 보 호성 방어기전으로 교합력의 감소를 초래한다고 생각된다[27]. 교정치료 중에는 치아의 이동으로 인해 교합이 안정되지 않고, 치주조직의 기계수용체 및 근육조직의 변화로 인해 교합력이 낮게 나타나며, 교정치료가 종료된 이후에는 교합력이 증가됨 을 보고하였다[23]. Yoon 등[28]은 발치를 시행하지 않은 군과, 상악 양측 소구치를 발치한 군, 상하악 양측 총 4 개의 소구치를 발치한 군으로 나누어 교합력을 비교한 연구를 시행하였다. 교 정치료 전, 교정치료 종료 직후 및 치료 종료 2년 후의 교합력을 비교하였을 때 치료 직후에는 치료 전에 비해 교합력이 현저히 감소하였다가 치료 종료 2년 후에는 다시 치료 전과 비슷한 정 도로 회복되었고, 세 군간의 통계적인 유의성은 관찰되지 않았 다고 보고하였다.

다른 연구에서는 교정치료 종료 후 사용하는 유지장치에 따 른 교합력의 변화를 관찰하였다. 상악과 하악에 각각 투명유지 장치(essix retainer), 상악 투명유지장치와 하악 전치부 고정식 유지장치, 환상유지장치(circumferential retainer)의 세 군으로 나누어 술후 6주와 10주의 교합력을 평가하였고, 투명유지장치 를 상하악에 장착한 군을 제외한 나머지 군에서는 교합력이 대 조군과 비슷한 정도로 회복되었으나 투명유지장치군의 경우는 교합력이 대조군에 비해 유의성 있게 저하되어 있는 것을 보고 하였다. 이러한 투명유지장치는 상악과 하악 치아의 직접적인 접촉을 저해하므로, 교합이 안정되지 않고, 근육의 기능 회복을 지연시킨다고 보고하였다[29].

\section{턱교정 수술과 교합력}

턱교정 수술 전후의 교합력을 평가한 많은 연구들이 이루어 
졌고, 사용한 교합력 평가방법, 측정부위, 환자의 교합상태 등 에 따라 다양한 결과들이 보고되었는데, 최근 보고된 연구에서 는 다양한 방법의 턱교정 수술법을 사용한 대부분의 연구에서 수술 후 초기 수개월 동안에는 전반적으로 최대 교합력의 감소 를 보이고, 이후 점진적으로 증가하여 정상 교합자와 비슷한 정 도로 회복되는 경향을 보인다고 하였다[30]. Iwase 등[31]은 턱 교정 수술을 받은 3 급 부정교합 환자의 교합력을 정상 교합자 인 대조군과 비교하였는데, Dental Prescale System을 이용하 여 초진, 수술 직전, 술후 6주, 3개월, 6개월, 1년, 2년의 교합력 을 각각 평가하였다. 술전 교합력은 남녀 모두 대조군에 비해 절 반 정도에 그쳤고, 수술 직전 및 술후 6주까지는 더 많이 감소하 였다가 점차 회복되어 술후 6 개월 이후로는 술전보다 높은 수치 를 나타낸다고 하였다, 2년이 경과할 때까지 교합력은 지속적으 로 증가하였으나 대조군에 미치지는 못하였다[31].

여러 연구에서 턱교정 수술 후 1-3년 후의 교합력은 수술 전 에 비해서 1.5-3배 정도 증가하는 것으로 보고하고 있다[32]. 교 합력의 증가는 여러 가지 요인에 의해 기인하는데 첫 번째는 수 술 후 근육의 활성이 증가하기 때문이다. 보통 술후 1 년 안에 근 육의 활성은 정상 교합자와 비슷한 정도에 도달한다고 알려져 있고, 1 년이 지난 이후로는 근육의 활성은 크게 증가하지 않는 다고 보고되었다[33]. 1년 이상 경과 후에도 교합력이 점진적으 로 증가하는 것은 교정치료를 통해 이루어진다고 생각된다. 대 부분 턱교정 수술과 동반하여 수술 전과 후의 교정치료가 이루 어지는데, 술전 교정 치료시기에는 수술 후의 교합상태를 고려 해 오히려 교합을 불안정하게 만드는 경우가 있기 때문에 술전 교정치료 기간에 교합력은 더욱 감소하게 되고[34], 술후 교정 치료를 통해 점차 교합되는 치아의 개수가 증가하고, 교합접촉 면적이 넓어지면서 교합상태가 전반적으로 안정화됨으로 인해 수술 후 1 년 이상 경과 후에도 교합력이 점진적으로 증가되게 된다[32].

\section{수복치료와 교합력}

치아의 상실은 최대 교합력의 감소와 연관이 있다. 최대 교합 력은 대합되는 치아의 수와 양의 상관관계를 보이기 때문에 치 아간 접촉수의 회복은 최대 교합력에 영향을 미치는 중요한 요 소이다[35]. 완전무치악 환자에서 기존 총의치를 이용한 수복치 료는 자연치열을 가진 사람의 최대 교합력의 $20 \%$ 정도 회복이 가능하다[36]. 임플란트를 식립하여 피개의치를 제작할 경우 기 존의 총의치에 비해 약 두 배 정도 높은 최대 교합력을 회복할 수 있다[37]. 완전 무치악 환자에서 교합력의 회복은 환자의 만 족도 향상과 관련이 있음이 보고되었다[38]. 임플란트를 이용한 수복치료를 통해 최대 교합력이 증가하는 것은 여러 연구를 통
해 보고되었다. Kwon 등[39]은 반대측에 자연치열을 가진 편악 무치악 환자에서 임플란트 수복치료를 시행하고 6개월과 12 개 월 후에 교합력이 유의하게 증가하며, 12 개월 이후에는 자연치 아의 최대 교합력을 회복함을 보고하였다. Melo 등[40]은 무치 악 환자에서 임플란트를 이용한 고정성 보철수복시 보철물 장 착 직후에 최대 교합력이 현저히 증가하였고, 3-5년 기능 후에 는 최대 교합력이 더욱 증가한 것으로 보고하였다.

성인에서 보철물을 이용한 수복치료뿐만 아니라 소아청소년 의 치료에서도 치아우식, 치조농양 등에 의해 감소된 최대 교합 력은 적절한 수복치료를 통해 회복됨이 보고되었다[41].

동통에 대한 두려움이나 치과치료에 대한 불안감과 같은 환 자의 주관적인 요소는 수복물의 반복적인 사용에 의하여 점진 적으로 적응이 되어야 심리적 안정을 얻게 되기 때문에 수복치 료 후 일정시간이 경과하여야 저작계의 회복과 함께 최대 교합 력이 증가하는 것으로 사료된다.

\section{측두하악장애, 교합장치와 교합력}

측두하악장애와 교합력의 연관성에 대한 많은 연구가 이루어 져 왔다. 여러 문헌에서 측두하악장애 증상이 있는 환자에서 교 합력이 낮게 나타남을 보고하였고, 이는 근육 통증 또는 턱관절 의 염증이 교합력을 감소시키는데 중요하게 작용하는 것으로 생각된다[42]. 또한, 여러 연구를 통해 측두하악장애의 치료 후 에는 교합력이 다시 회복되는 것이 보고되었다[43]. 교합장치치 료는 턱디스크 질환, 턱관절 및 근육 부위의 통증, 턱관절 골관 절염 등 다양한 종류의 측두하악장애의 치료에 널리 사용되는 술식이다. 교합장치는 턱관절에 가해지는 부하나 근육의 활성 을 감소시킨다고 알려져 있고, 이러한 교합장치의 사용과 교합 력의 연관성에 대해서도 연구가 이루어져 왔으나 다소 상반된 결과들이 보고되었다. 치아의 마모로 수직고경이 감소한 환자 에게 교합장치를 적용하고 교합력을 평가한 연구에서 장치치료 전에는 대조군에 비해 교합력이 현저히 낮게 나타났으며, 치료 후 교합력은 점차 증가하여 12 주 후에는 대조군과 유의한 차이 를 보이지 않았다[44]. 반대로 이갈이 환자에서 장치치료를 적 용하고 교합력이 감소함을 보고한 연구도 있다[45]. 이러한 상 반된 결과는 실험군의 설정 및 교합력을 측정하는 부위와 방법 의 차이 등에서 기인하는 것으로 생각된다.

\section{Discussion}

교합력은 환자의 저작계의 기능을 평가하는 방법 중 하나이 다. 환자의 치아나 치아지지 조직에서 발생된 질환은 통증이나 불편함을 야기하고, 이는 저작계 기능의 저하로 교합력이 감소 
하게 된다. 통증이나 불편함은 환자의 주관적인 증상이므로 객 관적인 평가나 기록이 어렵기 때문에 치과의사는 치과치료를 통해 증상이 개선되고, 교합력이 증가하는 것을 객관적인 수치 로 평가하기 위해서 노력하여 왔다. 본 연구에서는 교합력의 측 정 및 평가, 교합력에 영향을 주는 요인, 다양한 치과치료와의 연관성에 대하여 고찰해 보았다. 치과의사가 교합력과 관련한 다양한 저작계 요소의 의미를 이해하고, 임상술식에 적용하는 것은 환자의 치료에 도움이 될 것으로 사료된다.

\section{Conflicts of Interest}

The authors declare that they have no competing interests.

\section{ORCID}

\author{
Jin-Kyu Kang \\ https://orcid.org/0000-0001-7668-7468 \\ Jin-Han Lee \\ https://orcid.org/0000-0001-9360-0635
}

\section{References}

1. Koc D, Dogan A, Bek B. Bite force and influential factors on bite force measurements: a literature review. Eur J Dent 2010;4:223-232.

2. Palinkas M, Nassar MS, Cecílio FA, Siéssere S, Semprini M, Machado-de-Sousa JP, Hallak JE, Regalo SC. Age and gender influence on maximal bite force and masticatory muscles thickness. Arch Oral Biol 2010;55:797-802. doi: 10.1016/j.archoralbio.2010.06.016.

3. Sathyanarayana HP, Premkumar S, Manjula WS. Assessment of maximum voluntary bite force in adults with normal occlusion and different types of malocclusions. J Contemp Dent Pract 2012;13:534-538. doi: 10.5005/jpjournals-10024-1181.

4. Okeson JP. Management of temporomandibular disorders and occlusion. 7th ed. St. Louis: Elsevier; 2013;33-34.

5. Waltimo A, Könönen M. A novel bite force recorder and maximal isometric bite force values for healthy young adults. Scand J Dent Res 1993;101:171-175. doi: 10.1111/ j.1600-0722.1993.tb01658.x.

6. Kovero O, Hurmerinta K, Zepa I, Huggare J, Nissinen M, Könönen M. Maximal bite force and its associations with spinal posture and craniofacial morphology in young adults. Acta Odontol Scand 2002;60:365-369. doi: 10.1080/000163502762667405.

7. Kiliaridis S, Kjellberg H, Wenneberg B, Engström C. The relationship between maximal bite force, bite force en- durance, and facial morphology during growth. A crosssectional study. Acta Odontol Scand 1993;51:323-331. doi: 10.3109/00016359309040583.

8. Owais AI, Shaweesh M, Abu Alhaija ES. Maximum occusal bite force for children in different dentition stages. Eur J Orthod 2013;35:427-433. doi: 10.1093/ejo/cjs021.

9. Roldán SI, Restrepo LG, Isaza JF, Vélez LG, Buschang PH. Are maximum bite forces of subjects 7 to 17 years of age related to malocclusion? Angle Orthod 2016;86:456-461. doi: 10.2319/051315-323.1.

10. Lee MS, Choi YC, Choi SC, Kim GC. A study of relationship between bite force, masseter muscle and craniofacial morphology: cephalometric \& ultrasonographic analysis. J Korean Acad Pediatr Dent 2008:35:399-417.

11. Gibbs CH, Mahan PE, Lundeen HC, Brehnan K, Walsh EK, Holbrook WB. Occlusal forces during chewing and swallowing as measured by sound transmission. J Prosthet Dent 1981;46:443-449. doi: 10.1016/0022-3913(81)90455-8.

12. Ferrario VF, Sforza C, Zanotti G, Tartaglia GM. Maximal bite forces in healthy young adults as predicted by surface electromyography. J Dent 2004;32:451-457. doi: 10.1016/ j.jdent.2004.02.009.

13. Ortuğ G. A new device for measuring mastication force (Gnathodynamometer). Ann Anat 2002;184:393-396. doi: 10.1016/S0940-9602(02)80063-2.

14. Linderholm H, Wennström A. Isometric bite force and its relation to general muscle forge and body build. Acta Odontol Scand 1970;28:679-689. doi: 10.3109/00016357009058590.

15. Koc D, Dogan A, Bek B, Yucel M. Effects of increasing the jaw opening on the maximum bite force and electromyographic activities of jaw muscles. J Dent Sci 2012;7:14-19. doi: 10.1016/j.jds.2012.01.002.

16. Proffit WR, Fields HW, Nixon WL. Occlusal forces in normal- and long-face adults. J Dent Res 1983;62:566-570. doi: 10.1177/00220345830620051201.

17. Gu Y, Bai Y, Xie X. Bite force transducers and measurement devices. Front Bioeng Biotechnol 2021;9:665081. doi: 10.3389/fbioe.2021.665081.

18. Araújo SCCS, Vieira MM, Gasparotto CA, Bommarito S. Bite force analysis in different types of angle malocclusions. Rev CEFAC 2014;16:1567-1578. doi: 10.1590/1982021620145113.

19. Custodio W, Gomes SG, Faot F, Garcia RC, Del Bel Cury AA. Occlusal force, electromyographic activity of masticatory muscles and mandibular flexure of subjects with different facial types. J Appl Oral Sci 2011;19:343-349. doi: 10.1590/s1678-77572011005000008.

20. Sonnesen L, Bakke M. Molar bite force in relation to occlusion, craniofacial dimensions, and head posture in preorthodontic children. Eur J Orthod 2005;27:58-63. doi: 10.1093/ejo/cjh069.

21. Turkistani KA, Alkayyal MA, Abbassy MA, Al-Dharrab AA, 
Zahran MH, Melis M, Zawawi KH. Comparison of occlusal bite force distribution in subjects with different occlusal characteristics. Cranio 2020 Oct 19 [Epub]. http://doi.org/ 10.1080/08869634.2020.1830662.

22. Bakke M. Bite force and occlusion. Semin Orthod 2006;12:120-126. doi: 10.1053/j.sodo.2006.01.005.

23. Sonnesen L, Bakke M. Bite force in children with unilateral crossbite before and after orthodontic treatment. A prospective longitudinal study. Eur J Orthod 2007;29:310-313. doi: 10.1093/ejo/cjl082.

24. Telich-Tarriba JE, Contreras-Molinar C, Orihuela-Rodriguez A, Lesta-Compagnucci L, Carrillo-Cordova JR, Cardenas-Mejia A. Bite force and electromyographic activity of the masseter muscle in children with hemifacial microsomia. J Plast Surg Hand Surg 2019;53:316-319. doi: 10.1080/2000656X.2019.1626737.

25. Karakis D, Aktas-Yilmaz B, Dogan A, Yetkin I, Bek B. The bite force and craniofacial morphology in patients with acromegaly: a pilot study. Med Oral Patol Oral Cir Bucal 2014;19:e1-e7. doi: 10.4317/medoral.18984.

26. Alomari SA, Alhaija ES. Occlusal bite force changes during 6 months of orthodontic treatment with fixed appliances. Aust Orthod J 2012;28:197-203.

27. Ahlberg JP, Kovero OA, Hurmerinta KA, Zepa I, Nissinen MJ, Könönen MH. Maximal bite force and its association with signs and symptoms of TMD, occlusion, and body mass index in a cohort of young adults. Cranio 2003;21:248-252. doi: 10.1080/08869634.2003.11746258.

28. Yoon W, Hwang S, Chung C, Kim KH. Changes in occlusal function after extraction of premolars: 2-year follow-up. Angle Orthod 2017;87:703-708. doi: 10.2319/112116-836.1.

29. Varga S, Spalj S, Anic Milosevic S, Lapter Varga M, Mestrovic S, Trinajstic Zrinski M, Slaj M. Changes of bite force and occlusal contacts in the retention phase of orthodontic treatment: a controlled clinical trial. Am J Orthod Dentofacial Orthop 2017;152:767-777. doi: 10.1016/ j.ajodo.2017.03.028.

30. Te Veldhuis EC, Te Veldhuis AH, Bramer WM, Wolvius EB, Koudstaal MJ. The effect of orthognathic surgery on the temporomandibular joint and oral function: a systematic review. Int J Oral Maxillofac Surg 2017;46:554-563. doi: 10.1016/j.ijom.2017.01.004.

31. Iwase M, Ohashi M, Tachibana H, Toyoshima T, Nagumo M. Bite force, occlusal contact area and masticatory efficiency before and after orthognathic surgical correction of mandibular prognathism. Int J Oral Maxillofac Surg 2006;35:1102-1107. doi: 10.1016/j.ijom.2006.08.014.

32. Nagai I, Tanaka N, Noguchi M, Suda Y, Sonoda T, Kohama G. Changes in occlusal state of patients with mandibular prognathism after orthognathic surgery: a pilot study. $\mathrm{Br}$ J Oral Maxillofac Surg 2001;39:429-433. doi: 10.1054/ bjom.2001.0681.

33. Raustia AM, Oikarinen KS. Changes in electric activity of masseter and temporal muscles after mandibular sagittal split osteotomy. Int J Oral Maxillofac Surg 1994;23:180184. doi: 10.1016/s0901-5027(05)80297-8.

34. Thomas GP, Throckmorton GS, Ellis E 3rd, Sinn DP. The effects of orthodontic treatment on isometric bite forces and mandibular motion in patients before orthognathic surgery. J Oral Maxillofac Surg 1995;53:673-678; discussion 678-679. doi: 10.1016/0278-2391(95)90168-x.

35. Lassila V, Holmlund I, Koivumaa KK. Bite force and its correlations in different denture types. Acta Odontol Scand 1985;43:127-132. doi: 10.3109/00016358509064142.

36. Miura H, Watanabe S, Isogai E, Miura K. Comparison of maximum bite force and dentate status between healthy and frail elderly persons. J Oral Rehabil 2001;28:592-595. doi: 10.1046/j.1365-2842.2001.00716.x.

37. van Kampen FM, van der Bilt A, Cune MS, Bosman F. The influence of various attachment types in mandibular implant-retained overdentures on maximum bite force and EMG. J Dent Res 2002;81:170-173. doi: 10.1177/154405910208100305.

38. Rismanchian M, Bajoghli F, Mostajeran Z, Fazel A, Eshkevari Ps. Effect of implants on maximum bite force in edentulous patients. J Oral Implantol 2009;35:196-200. doi: 10.1563/1548-1336-35.4.196.

39. Kwon YS, Hwang SH, Han DH. Comparison of maximum occlusal forces on osseointegrated implant supported fixed prostheses and natural teeth. J Korean Acad Prosthodont 2005;43:498-510.

40. Melo ACM, Ledra IM, Vieira RA, Coró ER, Sartori IAM. Maximum bite force of edentulous patients before and after dental implant rehabilitation: long-term follow-up and facial type influence. J Prosthodont 2018;27:523-527. doi: 10.1111/jopr.12544.

41. Singh R, Singh S, Jha A, Jha S, Singh AK, Kumar S. Comparative evaluation of bite force in paediatric patients. J Family Med Prim Care 2020;9:2002-2005. doi: 10.4103/ jfmpc.jfmpc_1135_19.

42. Kogawa EM, Calderon PS, Lauris JR, Araujo CR, Conti PC. Evaluation of maximal bite force in temporomandibular disorders patients. J Oral Rehabil 2006;33:559-565. doi: 10.1111/j.1365-2842.2006.01619.x.

43. Pereira LJ, Steenks MH, de Wijer A, Speksnijder CM, van der Bilt A. Masticatory function in subacute TMD patients before and after treatment. J Oral Rehabil 2009;36:391402. doi: 10.1111/j.1365-2842.2008.01920.x.

44. Jain V, Mathur VP, Abhishek K, Kothari M. Effect of occlusal splint therapy on maximum bite force in individuals with moderate to severe attrition of teeth. J Prosthodont Res 2012;56:287-292. doi: 10.1016/j.jpor.2012.05.002.

45. Alkan A, Bulut E, Arici S, Sato S. Evaluation of treatments in patients with nocturnal bruxism on bite force and occlusal contact area: a preliminary report. Eur J Dent 2008;2:276282. 